\title{
Imaginario prometeico y vanguardia de Valparaíso: Exploraciones entre modernidad y metrópolis en la poesía de Pedro Plonka*
}

Promethean imaginary and avant-garde of Valparaíso: Explorations among modernity and metropolis in the poetry of Pedro Plonka

\section{Hugo Herrera Pardo}

Pontificia Universidad Católica de Valparaíso. Valparaíso, Chile

hugo.herrera.pardo@gmail.com

\section{RESUMEN}

Este artículo examina las distintas posiciones -ya sea de convergencia, divergencia o disensión- que toman las representaciones de la Modernidad en dos poemas - "El viento y la multitud en la metrópolis" y “Maniobra gris (niebla en el puerto)"- de Pedro Plonka, integrante de la vanguardia histórica literaria desarrollada en Valparaíso. En estos poemas se aprecia un progresivo distanciamiento del imaginario prometeico que motivó la fe en el progreso y en la técnica incentivando con ello el crecimiento industrial, comercial y marítimo de la ciudad desde fines del siglo XIX hasta las primeras décadas del siglo pasado. Por medio del análisis de las mediaciones en los textos literarios apreciamos que se construye en ambos poemas un imaginario que socava aquel imaginario prometeico, entregando una visión de crítica, y no así de fracaso, de la acelerada y progresiva concepción de tiempo histórico propia de la modernidad.

Palabras clave: Vanguardias históricas, imaginario, modernización, metrópolis, mediaciones.

*Artículo desarrollado al interior del Proyecto Fondecyt 1085201 "Constelaciones del imaginario local en la literatura de Valparaíso (1888-1989): Procedencias y emergencias para una historia efectiva", cuyo investigador responsable es el Dr. Adolfo de Nordenflycht. 


\section{ABSTRACT}

This article examines the various positions, either convergence, divergence or dissent, they take representations of modernity in two poems - "The wind and the multitude in the metropolis" and "Maneuver gray (mist on the port)"- from Pedro Plonka, a member of the historical avant-garde literature developed in Valparaíso. In these poems can be seen a gradual distancing from the Promethean imaginary that led to the belief in progress and technique thus encouraging industrial growth, trade and shipping in the city since the late nineteenth century until the early decades of last century. Through the analysis of literary texts mediating appreciate being built in both poems a imaginary that undermines that Promethean imaginary, providing a critical view, and not of failure, the rapid and progressive conception of historical time itself modernity.

Keywords: Historical avant-garde, imaginary, modernization, metropolis, mediations.

Recibido: 12.01.2011. Aceptado: 24.04.2011.

\section{SUCESIVIDAD DE MODERNIDADES Y VANGUARDIAS LOCALES}

-1 presente trabajo mantiene como objetivo general explorar algunos as$\mathcal{L}$ pectos de las relaciones e implicancias entre Modernidad y Metrópolis en las vanguardias locales, entendiendo por esto último a vanguardismos desarrollados en espacios urbanos reducidos en extensión física y ostentación de poder político-administrativo a escala "nacional", pero en el que efectivamente se intersectan las dos matrices conformadoras de Modernidad: por un lado la modernización, es decir, los procesos "de cambio y desarrollo social más concretos y objetivos" (Soja, 2008: 119) tales como industrialización, urbanización, racionalización y tecnología -en sus distintos grados de mayor o menor desarrollo- que atraviesan de manera transversal la sucesividad de modernidades y, por otra parte, el modernismo, comprendido como "las diversas respuestas culturales, ideológicas y reflexivas a la condición" (Soja, 2008: 119) de "conciencia práctica" que de acuerdo a Marshall Berman (1997) define y caracteriza a la Modernidad ${ }^{1}$, siendo estas respuestas

${ }^{1} \mathrm{Al}$ interior de las historias referidas a las vanguardias latinoamericanas, sin duda que las dos vanguardias locales más reconocidas son las desarrolladas en Puno, Perú, por el grupo Orkopata fundado por los hermanos Alejandro y Arturo Peralta (Gamaliel Churata) editores del Boletín Titikaka (34 números entre 1926 y 1930) y la vanguardia desarrollada por el Grupo Verde en Cata- 
en el caso concreto de las vanguardias refutaciones opositoras tanto a las instituciones artísticas como al mismo sistema social ${ }^{2}$. Sin embargo, estas vanguardias locales, en el marco de los estudios literarios, han sido por lo general subsumidas, en algunos casos hasta la obliteración, en el intento de establecer directrices interpretativas de una vanguardia de carácter "nacional" que por lo general se reduce a su respectiva capital ${ }^{3}$. Tal es el caso de la vanguardia histórica específica a la que se abocarán estas notas, la vanguardia desarrollada en Valparaíso desde comienzos de la década del veinte del siglo pasado, cuya escasa presencia en la bibliografía correspondiente se reduce en considerar el Manifiesto Rosa Náutica (1922), uno de los primeros publicados en Chile o comentarios escuetos aparecidos en antologías de poesía chilena como el que algunos de sus poetas como Neftalí Agrella, Guillermo Quiñónez, Jacobo Danke y Pedro Plonka, entre ellos, merecerían mayor atención por parte de la crítica. De forma más precisa, es en este último poeta $^{4}$ en el que centraremos nuestra reflexión y específicamente en dos de los cinco poemas de su "superviviente" producción que se conservan hasta hoy ${ }^{5}$, los cuales aparecieron publicados a mitad de los años cuarenta en los

guazes, Brasil, quienes publicaron la Revista Verde (seis números entre 1927 y 1929).

2 Para diferenciar las vanguardias de otras respuestas culturales de la modernidad utilizo la apreciación de Williams (1997), quien reconoce tres avanzadas de formaciones artísticas desde fines del siglo XIX. En primer lugar, grupos innovadores y defensivos que intentaron potenciar una determinada concepción de arte frente a la institucionalidad artística; luego la aparición de grupos que de manera alternativa intentaron potenciar sus producciones artísticas; y finalmente grupos con propuestas opositoras a la institucionalidad artística y social que podemos identificar como el periodo de las vanguardias históricas.

${ }^{3}$ Por ejemplo, en un breve ensayo titulado "Vanguardias del continente" Ana Pizarro sintetiza de la siguiente forma el itinerario crítico sobre las vanguardias históricas latinoamericanas: "Empezamos interesándonos por la gran poesía: Huidobro, Vallejo, el primer Borges, para luego comenzar a percatarnos que en cada país del continente hubo un movimiento, un grupo, una publicación de vanguardia que ponía [...] profunda fe en la transgresión, en la transformación tecnológica generadora de violentos cambios en la noción del tiempo y el espacio, en una devoradora ansia de "lo nuevo" como valor absoluto, que permitía instalarse de lleno en la modernidad" (Pizarro, 1994: 249, la cursiva es nuestra).

${ }^{4}$ Pedro Plonka (Pedro Valenzuela Páez, Valparaíso, 1896-1976). Al igual que pasa con su poesía, se conservan escasos datos biográficos sobre Plonka. En De carne y sueño. Memorias del Valparaíso de ayer (1995) Alfredo González cuenta que Plonka perteneció a la bohemia artística porteña de las primeras décadas del siglo XX, de la que pasado mitad de siglo se alejó silenciosamente. Escribió y reescribió (tras constantes destrucciones del manuscrito) un poemario, Latitud de siringüeros, que nunca llegó a publicarse.

${ }^{5}$ De entre los poetas que integraron la vanguardia porteña, sin duda son Julio Walton y Pedro Plonka de quienes se conservan en la actualidad menor cantidad de registros discursivos. La afirmación no es banal si consideramos que una de las características de la vanguardia poética de Valparaíso, con excepción quizás de Danke y algún otro, es la conservación de ésta en fragmentos sedimentados de textos perdidos, inencontrables, en algunos casos, no pocos, inéditos, y dentro de estos últimos, como costumbre de todas las vanguardias, cabe contar una multiplicidad de textos 
dos primeros números de la revista "Caballo de fuego". En aquellos dos poemas aludidos, "El viento y la multitud en la metrópolis" y "Maniobra gris (niebla en el puerto)", puede leerse el "frenetismo" y luego la "resaca" de los procesos de modernización en Valparaíso. En este sentido, la hipótesis presentada aquí es que la participación de elementos naturales como mediadores de los procesos de modernización resulta ser una de las posibles marcas diferenciales de la vanguardia histórica de Valparaíso, y que en el contexto cultural de la ciudad viene a socavar el imaginario prometeico ${ }^{6}$ surgido tras la modernización del puerto por parte de capitales extranjeros a mediados de siglo XIX. Sin embargo, antes de fundamentar esta posición, cabe establecer algunas puntualizaciones sobre la relación entre el concepto de imaginarios y el análisis propiamente literario.

\section{BREVE PARÉNTESIS: IMAGINARIOS Y ANÁLISIS LITERARIO}

Existe en la palabra imaginario -al menos en español y francés, de acuerdo a la noticia que nos entrega Solares (2006) - una superposición de lenguaje común y lenguaje teórico, entre "categoría de palabra" y "categoría conceptual" a decir de Bal (2009) que en el plano de las ciencias sociales ha provocado una polisemia tal que ha acabado generando una consideración peyorativa del término. El fuerte contenido intuitivo de imaginario ha contribuido a crear una confusión con conceptos tales como mentalidad, mitología, ideología, ficción, imaginería, entre otros (Wunenburger, 2000). Podemos inferir del planteamiento de Castoriadis que uno de los motivos de tal confusión es el doble funcionamiento de la palabra como adjetivo, en opinión de Castoriadis en los textos de Sartre y Durand, tanto como sustantivo, función esta última que procura conceptualizarla en su teoría sobre el imaginario. Para ello propone revisar la etimología de la

sólo enunciados que nunca llegaron siquiera a escribirse. De Walton (1889- ¿?), por ejemplo, que además de poeta, dibujante y editor, fue fundador junto a Neftalí Agrella de la editorial de "arte nuevo y literatura libre" Tour Eiffel, que inició y clausuró su catálogo con la publicación $\mathrm{La}$ tentación de los asesinos del húngaro Zsigmond Remenyik, sólo se conserva el poema rescatado por Lazslo Scholz "El aullido de las rameras", además de una pieza de teatro titulada El hijo de nadie y unas "Notas para una biografía de Neftalí Agrella" fechadas en 1933.

${ }^{6}$ Por imaginario prometeico entendemos, de modo general e introductorio, el conjunto de prácticas -sobre todo materiales, pero también discursivas-, por un lado filantrópicas y por otro anarquistas, que se desarrollaron en la ciudad tras la independencia del país, aunque con mayor fuerza hacia mediados del siglo XIX con la inversión de capitales extranjeros que convirtieron, en ese momento y hasta las primeras décadas del siglo XX, a Valparaíso en el primer puerto del Pacífico sur (De Nordenflycht, 2009). 
palabra imaginación:

(...) en vista de sus dos connotaciones: la conexión con la imagen en el sentido más amplio (pero no solo "visual") del término, es decir con la forma (Bild, Einbildung, etc.); y la conexión con la idea de invención, o hablando con propiedad, de creación.

Uso el término radical en primer lugar para oponer a lo que denomino a la imaginación "segunda", la única de la que habitualmente se habla, imaginación meramente reproductiva y/o combinatoria, y luego para subrayar la idea de que esta imaginación radical viene antes de la distinción entre "real" e "imaginario" o "ficticio". Para decirlo con todas las letras: es porque hay imaginación radical e imaginario instituyente que para nosotros hay "realidad" - a secas- y tal realidad.

Estas dos consideraciones se aplican al imaginario radical social instituyente. Radical porque crea ex nibilo (no in nibilo ni cum nibilo). No crea imágenes en el sentido habitual (aunque también las cree: postes totémicos, banderas, escudos, etc.) sino formas que pueden ser imágenes en sentido general (así eso hablamos de la "imagen acústica” de una palabra), que centralmente son significaciones e instituciones que son siempre solidarias. Aquí el término imaginario es un sustantivo rotundamente referido a una sustancia; no un adjetivo que denote una cualidad (Castoriadis, 1998a: 268).

Imaginario en tanto creación de "significaciones sociales imaginarias" tales como nación, estado, dinero, capital, real, ficticio, racional, etc., siendo significaciones imaginarias por que por lo demás no quedan agotadas en la referencia a estas nociones, y significaciones sociales porque solo existen de manera tal estando instituidas por la sociedad y "siendo objeto de participación de un ente colectivo impersonal y anónimo" (Castoriadis, 1998b: 68). Imaginario, finalmente, como construcción de un sistema interpretativo que nombramos por sociedad y que se dinamiza en constantes estados de "lo instituido" y "lo instituyente".

En el plano estrictamente literario, el problema sobre los imaginarios deviene como un problema metodológico, debido a que un uso intuitivo de esta noción lleva a los estudios literarios al plano de la sociología de la literatura, como sucede con mucha recurrencia en los artículos que pretenden el tratamiento de los imaginarios en los textos literarios, apartándolos de su estatuto específico como crítica. Una de las posibles salidas a este aspecto problemático, pienso, puede provenir de la crítica de carácter socio- 
lógico -no sociología de la literatura- en su desarrollo del papel que juegan estas "significaciones sociales imaginarias" en la constitución de las formas artísticas, es decir como "formadores de estructura" en palabras de Antonio Cándido (2006). Esto es, el proceso en el que elementos significativos del material psicológico y social ingresan al texto artístico de forma tal que éste es transformado y expresado a la vez, un proceso en el que para García Berrio el texto artístico "retiene en su estructura material, en su esquema verbal, solo el testigo físico de una actividad sígnica e imaginaria de expresión y de intercambio comunicativo mucho más compleja y extensiva" (García Berrio, 1994: 432) y que Cándido considera "una lectura orientada por los rasgos culturales y sociales incorporados a la estructura literaria (Cándido, 1991: 347). En diversos artículos el mismo Cándido desarrolla como herramienta metodológica para aprehender este proceso el estudio de las mediaciones en el análisis literario, herramienta que ofrece como capacidad heurística apoyar el tránsito desde el análisis a la interpretación, al dinamizar y poner en relación los elementos de análisis como los sistemas topológicos, las relaciones temporales, de voces al interior de los discursos, etc., al, como indica Williams (2003), describir una interacción como sustancial, con formas propias, con el objetivo de que no termine siendo un "proceso neutral de interacción de formas separadas", sino que por el contrario, "un proceso activo en el que la forma de la mediación modifica las cosas mediadas o indica la naturaleza de éstas por su propia naturaleza” (221). De este modo creemos se puede llevar a cabo una manera de acceder al funcionamiento de las "significaciones sociales imaginarias" en los textos artísticos.

\section{MODERNIDAD: UNIDAD Y DIVERSIDAD}

La posición investigativa de establecer las características de una vanguardia de carácter "nacional" se encuentra estrechamente ligada al proyecto de la Modernidad; son diversos los autores que sostienen que es de hecho la emergencia de la nación la que consolida a este proceso. No obstante, pensarla, como históricamente se ha pensado, a la Modernidad como un fenómeno homogéneo y simultáneo, es al menos deficitario. De acuerdo a Renato Ortiz (2001), se trata más bien de un fenómeno múltiple, en tanto se realiza de manera distinta en correspondencia con las condiciones históricas de cada lugar, por ello la modernidad es a la vez, para el autor, una y diversa. Una, en cuanto a procesos que le son consustanciales (lo anteriormente presen- 
tado como modernización); diversa, en su configuración histórica, sujeta a un tiempo-espacio particular que le asigna diferencialidad a cada proceso. Por tanto, la modernidad no corresponde a un proceso mimético que se transmita a nivel escalar desde las metrópolis de turno a los bordes, ninguna modernidad resulta modelo para las otras, ya que no es un fenómeno que se desarrolla por imitación, se trata más bien de un conjunto de cambios internos, correspondientes a una "lógica interna", a decir de Morse (2005), en las historias específicas de cada país.

La crítica literaria latinoamericana en diversos artículos y recopilaciones críticas de manifiestos y textos programáticos de las vanguardias históricas del continente aparecidos en las últimas décadas -Osorio (1988), Verani (1986), Cruz (1997), por citar algunos- ha usado esta posición para establecer la diferencialidad de ésta con respecto a las vanguardias europeas, alejándolas de una posible condición de epifenómeno. No obstante, aquella "lógica interna" no sólo se desarrolla a nivel de países, sino que también a nivel de comunidades locales al interior de éstos, por lo que dicha posición debería también ser extensiva a otros espacios urbanos que participaron como "arenas culturales" (Morse, 2005), al menos en algún momento del proceso de lo moderno, lo que las convierte en especies de, utilizando un concepto de Foucault, "heterotopías crónicas" de la Modernidad, es decir, espacios otros que ostentan esta condición por un periodo de tiempo fugaz, transitorio, sosteniendo este sitial mientras sus ventajas geográficas y naturales fueron funcionales a las metrópolis del momento. Llegados a este punto cabe aclarar que este enfoque de estudios no pretende desarticular la categoría de vanguardia nacional, sino que rearticularla develando relaciones e interacciones que históricamente les son propias, nos referimos a los vínculos que en su momento estrecharon las vanguardias locales con los grupos $\mathrm{y}$ poetas que desarrollaban movimientos vanguardistas desde la capital $-\mathrm{y}$ también desde otras capitales. En el caso específico que refiere a las vanguardias de Santiago y Valparaíso resultan ejemplares el hecho de que los dos poetas firmantes del primer manifiesto - presentado como tal- de carácter nacional, Agú, 1921 de Alberto Rojas Jiménez y Martín Bunster, aparecen al año siguiente firmando el manifiesto porteño Rosa Náutica, o los vínculos de Pablo de Rohka con Guillermo Quiñónez y Pedro Plonka o también el intercambio de publicaciones entre las revistas Gong (Valparaíso), Carcaj (Antofagasta), Acronal (Antofagasta), Mástil (Santiago), Letras (Santiago), por mencionar algunas en el plano nacional, y también intercambios internacionales de Gong con Amauta y Siempre, ambas desde Lima. 


\section{VALPARAÍSO-METRÓPOLIS}

La proliferación tanto semántica como material de Metrópolis entrevista más arriba ya había sido avizorada por Raymond Williams en un ensayo sobre las implicancias de las percepciones surgidas en las Metrópolis y el desarrollo del modernismo, al enunciar que:

Por una serie de razones sociales e históricas, la metrópoli de la segunda mitad del siglo XIX y la primera mitad del siglo XX ingresó en una dimensión cultural completamente nueva. Ahora era mucho más que una ciudad muy grande o incluso la capital de una ciudad importante. Era el lugar donde comenzaban a formarse nuevas relaciones sociales, culturales y económicas, más allá de la ciudad y la nación en su sentido más antiguo: una fase histórica distinta que en la segunda mitad del siglo XX iba a extenderse, al menos potencialmente, a todo el mundo (Williams, 1997: 65).

Ante este fenómeno, para Williams, una metodología apropiada tendría que explorar las muchas variaciones de dicho proceso desde diferentes perspectivas, no solo desde la comodidad del centro, sino también desde la ajenidad y la distancia, es decir, auscultar la metrópolis -término que en un comienzo fue pensado para expresar las relaciones entre naciones en el mundo neocolonial, y que pronto pasó a convertirse en el centro irradiador de las economías técnicamente avanzadas y dominantes- como "una forma histórica específica, en diferentes escenarios” (Williams, 1997: 68).

La poesía de Pedro Plonka (1945) traslada esta forma histórica específica a Valparaíso, en un momento en que la ciudad comienza a adolecer la resaca del febril auge modernizador que experimentara desde mediados del siglo XIX y que empieza a decaer tras la Primera Guerra Mundial. En su poema "El viento y la multitud en la metrópolis" dedicado a Valparaíso la invoca como "Metrópolis azul", "Capitanía del sur pacífico", "Metropolitana epidermis saturada de electricidad", en la cual se desenvuelve de manera vertiginosa la lógica de la modernidad que apunta a la universalización de los modos de producción. En el Valparaíso de Plonka: "Por las antenas inalámbricas huyen danzando las/ palabras/ y dirigen torbellinos de arquitecturas por el éter las/ veletas;/ agítanse los meridianos, las matrices y los ascensores, / y, enderezadas hasta arquearse sobre sus hornos meta/ lúrgicos/ las fábricas alientan oasis de equipos industriales/" (26). Esta adopción de una modernidad efervescente asociada al maquinismo es característica al menos de las vanguardias históricas y para Subirats (1989) surgió en la con- 
ciencia artística de comienzos de siglo pasado bajo una doble dimensión; por un lado se reveló como un medio de poder técnico sobre la naturaleza y por otro significó un factor ordenador en un sentido social y simbólico al mismo tiempo, lo que trajo como consecuencia el restablecimiento de "aquella dimensión radical del progreso, concebido como identidad del desarrollo científico-técnico y moral, característico de la filosofía de la historia de la Ilustración" (57). En el plano de las vanguardias latinoamericanas, Raúl Bueno (1998) denominó a esta adopción de la metáfora maquinaria "modernidad simbólica", encargada de satisfacer las carencias a nivel de lo real, en la que se observan, siguiendo al autor, al menos tres momentos y/o funciones sociohistóricas: a) apoyar los procesos de modernización de tipo más material; b) solucionar por medio de simbolizaciones (relativas a transporte, comunicaciones, infraestructura, modos de producción), varias de las carencias o insatisfacciones que presentaba en Latinoamérica aquella modernidad material, y por último; c) criticar y desmantelar aquella misma modernidad simbólica por medio de otro conjunto de simbolizaciones, que ya no asiente a las versiones optimistas acerca de las metáforas maquinarias de las primeras vanguardias europeas.

En "El viento y la multitud en la metrópolis", la adopción de la modernidad se concibe por medio de un sistema de posiciones en conflicto, en el cual ninguno termina por reducir a otro, y en el que conviven tanto el júbilo como la crítica. Sin embargo, es la mediación de elementos naturales, en el caso particular del poema el viento, el que le asigna diferencialidad, una "lógica interna" a la representación de la modernidad porteña. Es el viento, por medio de reiterados vocativos quien "moviliza el aire del mundo", desplaza "enormes catedrales de profunda luz", es el "activo diapasón planetario", es en definitiva el viento quien "satura universalmente" a la ciudad, trayendo las lógicas y procesos de la modernización y en la que la multitud:

(...) bajo despavoridos cielos verdes y rojos ante el control automático de los calendarios que marcan augurios, triunfos y derrotas en el suceso de los acontecimientos;

entre cuerpos y banderas que para siempre organizan vida entre soles de cobre y aluminio y luceros de dulces fuegos, entre tormentas de alabastro y fabriles lunes góticas; siempre la multitud, cayendo en siniestros precipicios 
y alzándose cada día transitoriamente

con alegría y terror en el vacío de la diafanidad (25).

El fragmento entrega varias oposiciones a tener en cuenta. Por un lado, la actuación de la multitud "cayendo y alzándose, con alegría y terror en el vacío de la diafanidad", no obstante los sujetos de enunciación se presentan a lo largo del poema respondiendo a una de la lógica de la modernidad referente a la homogeneización. La construcción de sujetos de enunciación en el poema es siempre genérica: "multitud", "generaciones", "pueblos", "masas", "legiones". Es, en este sentido, que cobra mayor potencia la figura de "el viento" al proponer una mediación entre los elementos en conflicto, y en cuya mediación finalmente se establecerá un elemento diferencial con respecto a las representaciones de la modernidad en la formación de vanguardia latinoamericana. El viento establece otro ritmo, otra velocidad, distinta de la establecida por la industrialización que unificó horarios y creó una cultura de la puntualidad, propia del mundo moderno, siendo un factor determinante para ello la emergencia de nuevos transportes, como las vías de ferrocarril, ya que involucraron la coordinación de los desplazamientos (Ortiz, 2001). En el poema de Plonka es el viento quien media el proceso de modernización en la ciudad-puerto y con ellos también el desplazamiento de sus habitantes:

Circula la Multitud. La Multitud pasa en el Viento, el Viento ejecuta en el órgano de la atmósfera. Trenes verbales cargados de especulaciones silban por los alambres telefónicos.

El puntero del sol pule el diamante de las horas y un cuasimodo oculto y metálico canta un romance de relojes (27).

El "control automático de los calendarios" apuntado más arriba junto con el "cuasimodo oculto y metálico" son finalmente mediados por fuerzas de la naturaleza como el viento y el sol, fenómeno que termina por justificar el juicio crítico de Subirats sobre la metaforización relativa a la máquina frente a la naturaleza llevada a cabo por las vanguardias históricas:

(...) el conflicto entre racionalización integral de la cultura y la irracionalidad de sus fenómenos objetivos, o bien entre la utopía artística de la máquina como principio de un orden social armónico y la realidad de un 
desarrollo tecnológico agresivo, pone de manifiesto la pretendida superación tecnológica de la naturaleza como una falacia. Incluso allí donde la naturaleza exterior y humana pudiera ser totalmente sustituida por una naturaleza artificial -el proyecto insólito formulado por las vanguardias- el resultado sería ambiguo y paradójico. Una cultura completamente racionalizada con arreglo a criterios tecnológicos podría, ciertamente, celebrar su independencia respecto de la naturaleza, pero no se libraría del temor a ella, de la angustia producida por su fuerza incontrolable o de su superioridad respecto a las capacidades limitadas del individuo humano (Subirats, 1989: 76).

No obstante la posición crítica ante el principio racional que funda el maquinismo, "El viento y la multitud en la metrópolis" termina siendo un canto hacia el futuro, hacia el porvenir, como queda en evidencia al cierre del poema:

Y, surgirán los años y los años por legiones innumerables

y de sus jornadas de piedra dejarán en el mundo sucesos eminentes,

y tú, Oh, Valparaíso! campana geográfica en potencia argollada al Viento,

doblarás con tu voz de granito sonoro agrandado en los tiempos (27).

Según Subirats (1989), el principio racional que funda el maquinismo se presenta en las vanguardias históricas europeas también bajo la forma de un conflicto sin solución, que se representa por medio del caos y la destrucción, y que se encuentra asociado a un sentimiento histórico de angustia, desesperación y nihilismo. Este conflicto sin solución ante la modernidad en Valparaíso es retomado en "Maniobra gris (niebla en el puerto)" y alejado de representaciones de caos y destrucción toma la figura de la disolución, conformada por el encuentro de un "mar que existe envejeciendo cadenas y cetáceos" y, esta vez, un "sigiloso viento del S. W." que entra en Valparaíso, creando una niebla que recorren "estridentes arcángeles" y en donde

derrúmbanse livianos fare-

llones y las humaredas encanecen;

algas de polares aluminios, hacen hilanderías en las 
grúas

izando mórbidos velámenes hacia sonámbulas corrientes, incitando secuaces geografías y memoriales bitácoras, incitando el mirar inhibido de trashumantes cariátides y el vuelo abismal de fríos pájaros; vecindades antárticas acumuladas detrás del estuario fraguan el canto marítimo de presentes soledades; surgen disueltas dársenas de corrosiva anatomía, barcos de fúnebres portalones con cargamentos de muertos armiños, quietas tripulaciones y sutiles balumbas (23).

De las transversales imágenes lumínicas y el canto hacia el futuro que cierra "El viento y la multitud en la metrópolis" a las imágenes de la opacidad y el "canto marítimo de presentes soledades" que abre "Maniobra gris"; el desarrollo del conflicto en la representación de la modernidad porteña en la poesía de Plonka muestra sus contraefectos tomando la contrafigura de la "Niebla", imagen opuesta a la efervescencia y luminosidad de la maquinaria, niebla que

Licua la ciudad, sus edificios, los transeúntes, mis

zapatos;

licuado todo el bello oro eléctrico del otoño, amortajada la fruta familiar de las ventanas iluminadas, desaparecidas las plazas, los catedrales, las esquinas

filantes;

paralíticos el braceo de los relojes y el pregón ciudadano, huidas la Vía Láctea y la Cruz del Sur, ruedan lejos los epitafios siderales, lejos el Mar Pacífico son su espumante fauna de sirenas y tritones; luces, vientos, aguas, vegetales ausentes; los pájaros no tienen dónde posarse, porque están llenas de serpientes las copas de los árboles (23).

La crítica de la "modernidad simbólica" pensada por Bueno y que toma en su trabajo la figura del desmantelamiento adquiere en la poesía de Plonka la forma de la licuación, fenómeno que funde un metal, en este caso la metáfora maquinaria, sin llegar a descomponerlo, sino que separándolo de otros elementos, semantizado en el poema por medio de la desaparición de "las 
plazas, los catedrales, las esquinas filantes", de la huida de "la Vía Láctea y la Cruz del Sur", estructura de la licuación que le otorga una forma artística a los graduales procesos políticos y sociales que afectaron a Valparaíso desde comienzos de siglo XX, me refiero al terremoto de 1906, la apertura del Canal de Panamá en 1914, la aparición del salitre sintético a fines de la Primera Guerra Mundial , la política de "sustitución de las importaciones" llevada a cabo por el gobierno de Pedro Aguirre Cerda y, más tarde pero continuando con el mismo proceso, la concesión al vecino puerto de San Antonio de franquicias de Puerto Mayor en 1957, eventos que marcarán la decadencia de la febril actividad económica y financiera que identificó al Valparaíso decimonónico, y eventos que a su vez serán las matrices configuradoras de un imaginario decadentista en la literatura porteña que ha ido adquiriendo nuevas formas hasta nuestros días, resultando significativa la trayectoria in descenso del elemento viento en los imaginarios literarios de Valparaíso desde "Valparaíso, ciudad del viento" de Edwards Bello, al papel del viento en la enérgica imagen de "mareas del sur" de Salvador Reyes, o el viento como elemento fundante en "Fundación de Valparaíso" de Gonzalo Rojas, hasta la ciudad caracterizada tan solo como "corriente de aire" en las memorias de Alfredo González.

\section{COMENTARIOS FINALES: IMAGINARIO PROMETEICO Y DECLIVE}

La mediación de elementos de la naturaleza, de forma específica el viento, pero también otros como el mar y el sol, en la representación de los procesos de modernización en Valparaíso presenta antecedentes con anterioridad a los poemas de Plonka. Concretamente el viento se sitúa como metáfora de la modernización debido a sus semantizaciones relativas a la extensión, a lo completamente abarcable. En la formación de vanguardia, el Manifiesto Rosa Náutica, texto que inaugura las vanguardia literaria en la ciudad-puerto, establece y autoprograma, por una parte, que el grupo de firmantes tendrá "por norma la celeridad evolucional de la Rosa de los Vientos", así como también una estrecha imbricación con las metáforas maquinarias: "engranamos nuestro corazón al gran sistema nervioso de las máquinas futuras” (en Nómez, 2000: 360). En otro momento, ya casi al final del texto, el grupo de poetas firmantes se presenta como "hecatónqueros intelectuales" que "suben a las planicies del sol", haciendo referencia a las figuras de la mitología griega consideradas como deidades del mar. Precisamente este elemento, el 
mar, se presenta fundamental en el poema más reconocido de Alberto Rojas Jiménez, uno de los firmantes de Rosa Náutica, "Carta-Océano", en el cual el poeta utiliza la discursividad postal que le da título al texto, presentada por Blaise Cendrars como "un mensaje práctico de tarifa regresiva”, que se utiliza a bordo para tratar asuntos que no se tuvo tiempo de tratar antes de la partida, llevando mensajes para atrás, "ya que solo se puede usar en este sentido" (Cendrars, 1975: 215), es decir una forma discursiva a medio camino entre una primera modernidad y otra nacida tras el auge comunicacional de la segunda revolución industrial, y que a comienzos del siglo XX adquirió forma poética vanguardista ${ }^{7}$. En el poema de Rojas Jiménez, los recuerdos del sujeto de enunciado que conforman los asuntos que no se tuvo tiempo de arreglar antes de la partida están mediados por la memoria "que aprendió el curso de los trenes” y el viento “...múltiple/ que pierde la voz de los náufragos" en donde el hablante reconoce que "esparcí la hoguera rosada de los sueños" (en Nómez, 2000: 211). Inclusive contemporáneamente a estas figuraciones del viento en la formación de vanguardia, se encuentran las presentaciones de este elemento como figura potente y enérgica en la narrativa de Edwards Bello y en la primera poesía de Salvador Reyes ${ }^{8}$.

Estas tensiones entre naturaleza y tecnología en los poemas de la vanguardia de Valparaíso se presentan como un nuevo estadio de un imaginario prometeico en la ciudad-puerto y que puede sintetizarse en lo que Durand denomina el conflicto entre la Naturphilosophie -la exaltación de la naturaleza como un tópico de las artes en general hasta más menos el siglo XVIIIy la Kulturphilosophie -la exaltación de la técnica y el progreso tecnológico con fuerza desde el siglo XIX. La poesía de Plonka lleva a este conflicto a un nuevo plano: el de la historia. Al definir a Valparaíso como una metrópolis, la poesía de Plonka despliega figuras que permiten ser historiadas desde su sincronía 9 , para advertir las implicancias del proceso de modernización en sus representaciones. De forma sincrónica, la categoría metrópolis, auscultada en su examen por el viento, categoría diacrónica que hace confluir en su

${ }^{7}$ Entre la "Carta-Océano" de Cendrars y la de Alberto Rojas Jiménez debe también considerarse la famosa "Carta-océano" de Guillaume Apollinaire que introduce la forma postal en la estética vanguardista.

8 "Valparaíso, ciudad del viento" (1931) y "Mareas del sur" (1930), respectivamente.

${ }^{9}$ Como se sabe, la expresión corresponde a Cornejo Polar y aparece en la Introducción a su último libro Escribir en el aire. Ensayo sobre la heterogeneidad socio-cultural en las Literaturas Andinas. Hace con ello referencia al hecho que el examinar discursos de conflictiva filiación socio-cultural "conduce a la comprobación de que en ellos actúan tiempos también variados; o si se quiere, que son históricamente densos por ser portadores de tiempos y ritmos sociales que se hunden verticalmente en su propia constitución, resonando en y con voces que pueden estar separadas entre sí por siglos de distancia” (2003 [1994]: 11). 
ritmo perpendicular, por una parte, vinculaciones con la memoria -lo que el viento trae consigo- y por otra, vinculaciones con el devenir -lo que el viento irriga, esparce. Al enunciarla como metrópolis, la poesía de Plonka afirma e institucionaliza a Valparaíso con la historia. El propósito de esta inserción responde que al no ser ya Valparaíso, por diferentes y graduales circunstancias, el "motor" de la historia nacional, como venía siéndolo desde fines de siglo XIX, debe buscar insertarse en el plano histórico para examinar qué nuevo lugar le corresponde y bajo qué nuevas condiciones.

En este sentido, la apreciación final que entrega la línea interpretativa sobre el conflicto naturaleza/tecnología en la vanguardia porteña, teniendo en consideración el carácter vanguardista de revalorización de lo específico de cada obra de arte en confrontación con los valores culturalmente instituidos, es presentar el declive bajo la forma de la falacia apuntada por Subirats en relación al conflicto en cuestión, lo que no quiere expresar que el declive en Valparaíso sea efectivamente una falacia, sino que apunta a mostrar desde el plano poético a aquella decadencia como crítica, en tanto la figura del viento en "El viento y la multitud en la metrópolis" y luego la estructura de la licuación en "Maniobra gris" desaceleran en su representación de la modernización lo que Koselleck (2003) denomina prognosis, esto es la experiencia de la aceleración del tiempo histórico como característica de la modernidad. De esta forma, al ralentizar activamente desde sus elementos culturales consustanciales, desde su "lógica interna", la modernidad velociferina-como la llama Faustino Encina, prologuista del ensayo de Koselleck- el declive de Valparaíso en la que culminan los dos poemas de Plonka dedicados a la ciudad se asume como crítica y no como fracaso del carácter progresivo y acelerado que, desde la concepción de historia surgida de la modernidad, debieran sostener los procesos de modernización. No obstante esta observación no debe quedarse sólo acá. Y es que la bitácora de la modernidad se encuentra poblada de críticas hacia su devenir en contextos bien distintos y distantes. En el caso de la crítica a la modernidad en los poemas de Plonka dada en la figura de la licuación, puede ser interpretada como una desarticulación del proceso moderno, una deformación de dicho proceso, figura de la deformación arraigada en el expresionismo y que de acuerdo a De Nordenflycht (2010) sería una de las diferencias más nítidas entre la vanguardia de Valparaíso y la vanguardia de Santiago marcada por el surrealismo. Es así entonces como en los dos poemas de Plonka dedicados a la modernización de Valparaíso la figura de la licuación en tanto deformación de algo propone confluir los rasgos sociales y artísticos de la "lógica interna" del espacio que representa y que a su vez se ve configurada y configurando tal acto. 


\section{REFERENCIAS}

Bal, Mieke. 2009. Conceptos viajeros en las humanidades. Una guía de viaje. Murcia: Cendeac.

Berman, Marshall. 1997. Todo lo sólido se desvanece en el aire. La experiencia de la Modernidad. México D. F: Siglo Veintiuno.

Bueno, Raúl. 1998. "La máquina como metáfora de modernización en la vanguardia latinoamericana”, en Revista de crítica literaria latinoamericana 48, pp. 25-37.

Cándido, Antonio. 1991. Crítica radical. Caracas: Ayacucho. 2006 [1965]. Literatura e sociedade. Río de Janeiro: Ouro sobre azul.

Castoriadis, Cornelius. 1998a. Hecho y por hacer. Pensar la imaginación. Buenos Aires: Eudeba.

1998b. Los dominios del hombre. Barcelona: Gedisa.

Cendrars, Blaise. 1975. Poesía completa. Buenos Aires: Ediciones Librerías Fausto.

Cornejo Polar, Antonio. 2003 [1994]. Escribir en el aire. Ensayo sobre la heterogeneidad socio-cultural en las Literaturas Andinas. Lima- Berkeley: Latinoamericana editores.

Cruz, Jacqueline. 1997. "Discursos de la modernidad en las culturas periféricas: la vanguardia latinoamericana”, en: Revista Hispamérica $\mathrm{N}^{\text {os }} 76-77$, pp. 19-34.

De Nordenflycht, Adolfo. 2009. "El imaginario de Valparaíso a mediados del siglo XX en Sábadomingo, novela de Juan Uribe, y en De carne y sueño, memorias de Alfredo González", en Revista Aisthesis No 45, pp. 154-166.

2010. "Escrituras locales en la periferia del canon: memoria de la vanguardia de Valparaíso". Ponencia leída en Encuentro Internacional de Poesía y Diversidades. Perspectivas críticas en el marco del Bicentenario, realizado en la Universidad de Chile los días 31 de agosto, 1 y 2 de septiembre de 2010.

García Berrio, Antonio (1994). Teoría de la Literatura. Madrid: Cátedra.

González, Alfredo. 1995. De carne y sueño. Memorias del Valparaíso de ayer. Valparaíso: Universidad de Valparaíso.

Koselleck, Reinhart. 2003. Aceleración, prognosis y secularización. Valencia: Pre-textos.

Morse, Richard. 2005. "Ciudades periféricas como arenas culturales (Rusia, Austria, América Latina), en Revista Bifurcaciones 3. [En línea] Disponi- 
ble en: http://www.bifurcaciones.cl/003/bifurcaciones_003_Morse.pdf. Consulta: 27.09.2011.

Nómez, Naín. 2000. Antología crítica de la poesía chilena. Tomo II. Santiago: LOM.

Ortiz, Renato. 2001. Modernidady espacio. Benjamin en París. Bogotá: Norma.

Osorio, Nelson. 1988. Manifiestos, proclamas y polémicas de la vanguardia literaria hispanoamericana. Caracas: Ayacucho.

Pizarro, Ana. 1994. De ostras y caníbales. Santiago: Universidad de Santiago. Plonka, Pedro. 1945. "El viento y la multitud en la metrópolis" y "Maniobra gris (niebla en el puerto)", en Revista Caballo de fuego 2, pp. 23-27. Soja, Edgard. 2008. Postmetrópolis. Estudios críticos sobre las ciudades y las regiones. Madrid: Traficantes de sueños.

Solares, Blanca. 2006. "Aproximaciones a la noción de imaginario", en Revista mexicana de ciencias politicas y sociales 198, pp. 129-141.

Subirats, Eduardo. 1989. El final de las vanguardias. Barcelona: Anthropos.

Verani, Hugo. 1986. Las vanguardias literarias hispanoamericanas. México: FCE.

Williams, Raymond. 1997. La politica del modernismo. Buenos Aires: Manantial.

2003. Palabras claves. Un vocabulario de la cultura y la sociedad. Buenos Aires: Nueva Visión.

Wunenburger, Jean-Jacques. 2000. "Lo imaginario de Gilbert Durand”. En Gilbert Durand, Lo imaginario. Barcelona: Ediciones del Bronce. 